Sharif, A.M. (2003). "Business is Joined-up Thinking". (Invited Viewpoint). Business Process Management Journal, 9 (4) : 555.

\title{
Business is Joined-up thinking
}

\author{
Amir M. Sharif \\ Information Systems Evaluation and Integration Group (ISEing) \\ Department of Information Systems and Computing, \\ Brunel University, \\ Uxbridge, UB8 3PH
}

Usually, when letters arrive by the now old-fashioned method of snail-mail, I look forward to opening the envelopes, enjoying the fact that I can still look forward to receiving messages and communications in a more traditional manner, without knowing the title, subject or mail addresses of the senders. Coupled with this is the fact that getting letters delivered to you personally, brings an air of excitement to the letter-opening experience: not knowing whether you are receiving a letter from a loved one, a happy birthday card, a tax rebate from the government (a simple wish...) or even the dread of seeing the most recent phonebill. So it was with great interest, that I picked up a rather anonymous looking blue envelope this morning, with a cryptic return postal address written on the reverse of it. Hoping for a surprise, I opened the letter to find out that I had been "cordially" invited to apply for an internet banking account from my bank, who I have been with now for the last 10 years. Since the launch of their eBanking division and services approximately 5 years ago, I have been a regular user of all of their online services. Obviously, my customer details do not appear on some database somewhere for some unknown reason. Or in their wisdom, my bank has decided to carpet bomb me with marketing material in the hope that even if I have defected from them to a rival bank, they can lure me back with their services. All of this prompted me to ask the question of why they did not realise that I was already an online account holder in the first place? More importantly, why are they wasting time and money sending me marketing material when I know (and they probably know somehow, somewhere) that I am registered as an eBanking user ?

The answer to this question I believe, is more to do with a lack of what is called 'joined-up-thinking' - the process of realising and implementing connected concepts and their respective solutions together. This phrase, made increasingly popular by politicians and their ilk, is more concerned with enabling complimentary socioeconomic strategies to be contained within larger, monolithic governmental policies. But the parallel with and relevance to business process enablement, is clear for those involved in MIS design. This is especially the case where Customer Relationship Management (CRM) systems are involved.

Over the recent months, many industry research analysts have mooted that the days of ill-conceived CRM implementations should now be behind us. Citing success stories from multiple sectors (online consumer websites, to multinationals in the pharmaceutical and airline industries to name a few), CRM vendors are also leading the charge to re-invigorate this technology solution. However, as the experience of Enterprise Resource Planning (ERP) has shown, the reality can be quite different. One cause of this can be quite put down to the clichéd concept of understanding the 
Sharif, A.M. (2003). "Business is Joined-up Thinking". (Invited Viewpoint). Business Process Management Journal, 9 (4) : 555.

requirements and matching them against what the technology solution can do. In many cases, this can be simply achieved usually at the expense of trimming the requirements to their bare bones, such that the functionality available in the software can be customised with the minimum of time and expense (especially when external consultants are involved). Obviously, this approach involves a radical normalisation of business processes which may inadvertently lead to a distortion of the real process being modelled. At the other extreme, the stance may well be taken that the business process is so critical, so involved and so intricate that the dilution of any single step may misrepresent the situation altogether. In either case, an inordinate amount of time can be spent in the analysis phase of the development lifecycle, where business process requirements can quite easily be optimised, reduction ad absurdum. This is even more important given the fact that many CRM vendors are experiencing revenue shrinkage from many of their traditional multinational clients, and may now have to roll up their sleeves to fight for the less lucrative but increasingly influential middle market of small and medium-sized enterprises. Clearly vendors such as Microsoft have pinned their hopes on this opportunity, by releasing their CRM offering around the Exchange and Outlook collaboration platform. It remains to be seen whether or not other vendors such as SAP can successfully migrate downstream, to a traditionally more discerning market who value closer integration between people, process and technology.

The problem with any representational view of a business lifecycle, is that there will inadvertently be times when key constraints or factors which impede or progress information flow, will be excluded. Many people would say these issues are better known as "bugs", others will see them as "requirements outside of the scope". In any case, there has not and I believe, will never be a holistic information systems methodology or approach which can truly represent the real business environment fully, without consigning additional factors such as indirect human costs and stakeholder relationships as overhead. So what are the options available to us, which will enable a better representation of information flow within and around people, processes and technology?

There are many approaches to thinking in a "joined-up" manner, which though not necessarily contributing to an overall methodological framework, can be used to uphold and augment existing process modelling techniques. Two particular approaches which may have been useful in the correct representation of my customer details in the banks' databases, could be Scenario Planning and / or Causal modelling. Scenario planning allows the resolution of a number of potential outcomes to a particular series of events, defined as a narrative (i.e. story) which can describes the situation best (for example, as is used in planning product marketing campaigns, such as in the FMCG sector). Causal or cognitive mapping, can also be a useful tool which can be used to investigate interrelationships between many different parameters at once (for example, as has been used to model dynamic systems, such as traffic flows within cities to IT/IS investment decision making). In any or either case, the implementation of the CRM system which targeted me as a potential customer for the online banking service, could simply have consisted of a logical "if-then-else" statement which may not have included any or all of the combinations of my complete relationship with the bank. Some level of fit between the strategic marketing plan and the operational customer data model, may well have yielded an analytical result which would intelligently screen me out of their overall campaign. 
Sharif, A.M. (2003). "Business is Joined-up Thinking". (Invited Viewpoint). Business Process Management Journal, 9 (4) : 555.

Where "joined-up" thinking comes into play for IT-enabled business processes, is in the understanding of not just the data (in this case me, as a customer or rather a customer number), and not just the information (if I have been a customer for more than 5 years, and if I fit into the 20-35 age group) - but the aggregation of both data and process models which form the basis of the system implementation. I am excluding for now the inherent, but growing realisation that emotional intelligence, where concepts such as brand loyalty, accounts for a growing amount of MIS feedback (which is a separate issue completely). Indeed, even in my limited experience, there have been very few, if any, projects where both the technical data model and the business process model have been put side by side and verified prior to implementation. A typical response from business users is that they do not care where or how the data is generated and stored, so long as it is stored in some manner, in preparation for some future requirement which has not been thought of, for a specific goal which has never been communicated. This level of verbosity regularly rears its head when the issue of management reporting occurs. Following numerous and protracted financial scandals which have occurred on Wall Street in the guises of Enron, Worldcom, Tyco and Global Crossing, such is the prominence now given to generating reports and scorecards on the state of the business as it progresses week by week, quarter by quarter.

But what is not understood and realised by those sponsors of business process integration and re-engineering, is the close integration that is required between data from diverse information sources within an enterprise. Agreed, this is a technical issue and one which needs to be resolved by those at the coal-face of MIS design. Naturally, those who are involved in the technical specification of systems such as on CRM-related projects which typically affect every and all facets of the business, are naturally more concerned and in touch with the low-level plumbing of IT/IS than the purely functional business analyst. So-called business intelligence or analytical CRM software, should give you the answer to this question - but then that presumes that the question you are asking is the right one. However, in order to encompass and eliminate the possibility of excessive reporting and adhoc changes to system functionality, there needs to be wholescale agreement on all aspects of computerising the business environment. And this requires an understanding of not only knowing the information content (i.e. knowing what and when information should be used), but also an appreciation of the context (i.e. the stakeholder) of that information within the overall business model

Which very neatly leads to the conclusion that joined-up thinking in some sense relies upon joined-up communication between process and implementation teams. In my online banking scenario, I am sure it would only involve integrating information from marketing, customer account and eBanking databases (if they be separated in the first place), to verify that I exist as a customer anywhere in the business at all. Of course, each of these sources could well belong to legally separate entities which could mean that the sharing of information would at best be impossible and at worst, prohibited entirely. But even if this is the case, it must surely become a business imperative to share and distribute such critical information. Perhaps this is not so much joined-up thinking, as joined-in thinking. 
Sharif, A.M. (2003). "Business is Joined-up Thinking". (Invited Viewpoint). Business Process Management Journal, 9 (4) : 555.

In any case, this state of nirvana that a management information system may exist in, should be such that it acts as the fuel which drives the enterprise ever forward (in the right direction of course). Through extending and including all facets of the business lifecycle within and throughout the infrastructure that supports it, a real attempt can be made to achieve the objectives of the organisation. And if the objective of my bank is to keep me as a customer, then at the very least, could they please see to it that they join up their thinking with mine in this article, and realise that I still log on to their site?

\section{Amir M. Sharif}

\section{Disclaimer}

The author wishes to assert that the views and opinions expressed in this article are solely those of the author. 